\title{
The Increased Frequency of the Lewis Negative Blood Group in a Diabetic Population
}

\author{
Ph. Vague ${ }^{1}$, C. Melis ${ }^{2}$, P. Mercier ${ }^{2}$, B. Vialettes ${ }^{1}$, and V. Lassmann ${ }^{1}$ \\ ${ }^{1}$ Diabetes Department, University Hospital Timone and ${ }^{2}$ Blood Transfusion Centre, Marseille, France
}

Summary. The Lewis negative (Le $a-b-$ ) red blood cell phenotype was observed three times more frequently in 170 diabetics $(29 \%)$ irrespective of their clinical type, than in 100 controls $(10 \%)$. This difference could not be accounted for by factors influencing the serological typing ("ABH secretion" and $A B O$ groups) nor by the geographic origin of the populations tested. The Lewis substances are primarily soluble antigens present in blood, saliva and other fluids and absorbed on red blood cells. In 61 diabetics saliva was also analysed. Blood cell and saliva results were concordant allowing the interpretation of the Lewis negative red cell phenotype to indicate the absence of the Lewis antigen. The higher frequency of the Lewis negative phenotype was not related to the severity or the duration of the diabetes and therefore was unlikely to depend on metabolic factors. It probably indicates an increased frequency of $(\mathrm{le}, \mathrm{le})$ genotype in the diabetic population. The similarity between the results for insulin dependent and insulin independent diabetes seems to indicate that these two clinical types of diabetes are genetically related.

Key words: Lewis blood groups, secretor status, diabetes.

Previous studies suggest the possibility of a blood group association to diabetes mellitus. It is likely that "juvenile" diabetes may be associated with group $O$ [1], while the maturity onset type appears associated with group A [2] and less so with group B [3]. But such associations are not uniformly observed [4]. However the study of histo-compatibility antigens (HLA system) gives strong evidence for the existence of a genetic heterogeneity between diabetics. The major susceptibility to insulin dependent diabetes irrespective of the age of onset seems to be conferred by genes in the HLA chromosomal region [5, 6], especially on the D locus determinant [7], while there is no association between HLA antigens and maturity onset or "insulin independent" diabetes. On the occasion of a HLA study [8] we screened for various red blood cell groups and observed incidentally an excess of the Lewis negative phenotype. An extension of this work has confirmed these results and will be reported here.

The Lewis antigens are primarily soluble substances present in plasma, saliva and other fluids. Red blood cells acquire these antigens passively. Therefore to determine if the lower frequency of Lewis antigens on the red blood cells of the diabetics was due to defective absorption on the erythrocyte or to failure to synthesise the antigens, saliva and red blood cells were studied concurrently in approximately one third of the diabetics.

\section{Subjects and Methods}

One hundred and seventy patients with overt diabetes were studied. One hundred and one were insulin dependent. Among them 87 belonged to the classical juvenile type (onset before the age of 30), 14 had a maturity onset diabetes but became insulindependent later on. At the time of the study they were aged from 51 to 77 . Sixty nine were stable, insulin independent maturity onset diabetics ranging in age from 37 to 74 . All these diabetics were unrelated.

The control population was made up of 100 blood donors whose red blood cells were phenotyped at the same time and with the same antisera as those of diabetics.

The blood groups ABO, Rhesus, MNS, P, Lutheran, Kell and Kidd were determined by routine methods [9]. The saliva of the diabetics was tested for secretion of ABH substances. It is known that the ability to secrete hydrosoluble group substances in saliva 
and other body fluids is genetically determined by a gene called Se and is shared by approximately $80 \%$ of the individuals. These subjects are called "secretors" [9]. The "secretors" with the Lewis genotype synthesise a Lewis (b) substance while a Lewis (a) substance is made up by "non secretors" with the Lewis genotype.

The Lewis group of the red blood cells was evaluated in duplicate with anti Lewis a and bL serum by the papain method [10, 11]. It is necessary to emphasize that there are two types of anti Le $b$ sera. One is named anti-Le bH and fails to react with Le b substance on red blood cells of Al group and is inhibited by saliva from $\mathrm{ABH}$ secretors, including saliva from persons of type $\mathrm{Le}$ ( $\mathrm{a}-$ $\mathrm{b}-$ ). The other one, anti $\mathrm{Le}-{ }^{\mathrm{bL}}$ reacts with $\mathrm{Le}^{\mathrm{b}}$ substance in the presence of group $\mathrm{Al}$ as well as $\mathrm{A} 2$ or $\mathrm{O}$. This antibody is not inhibited by saliva from subjects who lack Lewis substances whether or not they are "secretors". Anti Le ${ }^{\text {bL }}$ serum was used in this study.

The saliva diluted in equal volume of $0.154 \mathrm{~mol} / 1$ saline solution were heated to $56^{\circ} \mathrm{C}$ and then stored frozen. Their neutralizing capacity toward an anti Lewis a haemolyzing serum was studied at two dilutions. One drop of antiserum, 3 drops of saliva and inversely. Thirty minutes at room temperature were allowed for the neutralization to take place, then one drop of papainated Le a + red blood cells was added. After 30 minutes at $20^{\circ} \mathrm{C}$ haemolysis and some agglutination were observed with the Lesaliva which did not neutralize the antiserum. Known control salivas were run in parallel.

Statistical analysis was performed by the chi squared test using Yates correction.

\section{Results}

\section{Red Blood Cell Groups among Diabetics}

No difference was noted between diabetics, and controls for red blood cell groups except the Lewis groups.

Table 1 shows that the frequency of the Lewis negative (Le $a-b-$ ) phenotype was three times higher in diabetics irrespective of their clinical type than in controls. This increase in Le $(a-b-)$ phenotype corresponded to an equilibrated lower rate of $\mathrm{Le}(\mathrm{a}+\mathrm{b}-)$ and $\mathrm{Le}(\mathrm{a}-\mathrm{b}+)$ phenotypes.

\section{Lewis Phenotypes and "ABH Secretion" in Diabetics}

The percentage of Lewis negative results obtained may depend on the quality of the anti-Lewis serum used and it is known that anti-Lewis b sera are often less potent. "Secretors" with the Lewis genotype have Lewis (b) substance on their red blood cells, while "non-secretors" have Lewis (a) substance. One hundred and three diabetics were therefore assessed for their secretor status. Eighty were $\mathrm{ABH}$ "secretors" and 23 were not. Twenty two $(27.5 \%)$ were Lewis negative among the 80 "secretors" and 8 $(34.9 \%)$ among the "non secretors". As Lewis negative results were not found more often among "secretors" ( $\mathrm{X}^{2}=0.170 .7>\mathrm{p}>0.5$ not significant $)$ they could not be due to a poorly avid anti-Lewis $b$ serum.

\section{Lewis Phenotypes and A.B.O. Groups}

As an anti $\mathrm{Le}^{-\mathrm{bL}}$ serum was used no clear differences were expected between the results from $\mathrm{A}$ and $\mathrm{O}$ individuals. This appears in Table 2 where diabetics with group $\mathrm{A}$ and $\mathrm{O}$ were compared to 50 controls of group $\mathrm{O}$ and 50 of group $\mathrm{A}$. The difference between diabetics and controls persisted.

\section{Lewis Phenotypes and Ethnic Origin}

As the "le" gene occurs more frequently in Italian and North African populations our results might have been biased, since the Marseille population is cosmopolitan. We therefore classified the patients in three rough categories, North African (white people originating from Maghreb), "Mediterranean" (people originating from Spain, Corsica, Italy), and continental French. It is clear from Table 3 that the ethnic origin of the patients did not explain the high frequency of the Lewis negative phenotype, which was observed in all the subgroups of diabetics and not particularly in the North African one.

\section{Lewis Phenotype and Duration of the Diabetes}

In order to analyze if the duration of the diabetes could modify the Lewis phenotype, its distribution was studied among juvenile insulin dependent diabetics in whom the date of onset of the disease may be estimated with relative precision. Twenty five had diabetes for less than three years and among them 8 $(32 \%)$ were Lewis negative. Of twenty with diabetes for more than 10 years, $6(30 \%)$ were Lewis negative.

\section{Red Blood Cells and Saliva Lewis Antigens}

Blood and saliva were tested in 61 diabetics. 58 were concordant; 39 with Lewis antigens on the red blood cells and in the saliva, 19 lacking the Lewis antigen in both. In two cases no Lewis antigen was detected in the saliva while $a$ Le $(a-b+)$ appeared present on the red blood cells. Only one subject with Lewis antigen in the saliva gave a negative result with his erythrocytes. This small percentage of discordance may have been due to technical problems.

\section{Discussion}

An increased frequency of the Lewis negative phenotype was observed among diabetic individuals. However the chemical structure of the Lewis substance is modified by the "secretor" or "non se- 
Table 1

\begin{tabular}{lrllll}
\hline & $\mathrm{n}$ & $\begin{array}{l}\text { Lewis positive } \\
\text { Le(a+b-) }\end{array}$ & Le(a-b+) & $\begin{array}{l}\text { Lewis } \\
\text { negative } \\
\text { Le }(\mathrm{a}-\mathrm{b}-)\end{array}$ & $\begin{array}{l}\text { Difference } \\
\text { between test } \\
\text { and control }\end{array}$ \\
\hline All diabetics & 170 & 31 & 89 & $50(29.4 \%)$ & $\mathrm{p}<0.001$ \\
Insulin depend. diab. & 101 & 21 & 51 & $29(28.7 \%)$ & $\mathrm{p}<0.01$ \\
Insulin indep. diab. & 69 & 10 & 38 & $21(30.4 \%)$ & $\mathrm{p}<0.01$ \\
Controls (blood donors) & 100 & 19 & 71 & $10(10 \%)$ & \\
\hline
\end{tabular}

Table 2. Lewis groups in $\mathrm{O}$ and A diabetic and control individuals

\begin{tabular}{|c|c|c|c|c|c|c|}
\hline & \multicolumn{3}{|c|}{ O Group } & \multicolumn{3}{|c|}{ A Group } \\
\hline & $\bar{n}$ & Lewis & + Lewis $(-)$ & $\bar{n}$ & Lewis + & + Lewis $(-)$ \\
\hline Diabetics & 58 & $74 \%$ & $26 \%$ & 66 & $63 \%$ & $37 \%$ \\
\hline \multirow[t]{2}{*}{ Controls } & 50 & $94 \%$ & $6 \%$ & 50 & $86 \%$ & $14 \%$ \\
\hline & & & $\mathrm{p}<0.01$ & & & $\mathrm{p}<0.01$ \\
\hline
\end{tabular}

Table 3. Lewis groups and the ethnical origin of the diabetics

\begin{tabular}{lrrrr}
\hline & $\mathrm{n}$ & Lewis + Lewis - \\
\hline Diabetics & & & & \\
$\quad$ North African & 22 & 16 & 6 & $27 \%$ \\
Mediterranean & 70 & 51 & 19 & $27 \%$ \\
$\quad$ Continental French & 79 & 54 & 25 & $32 \%$ \\
Controls & & & & \\
$\quad$ North African & 5 & 4 & 1 & \\
$\quad$ Mediterranean & 34 & 30 & 4 & \\
$\quad$ Continental French & 56 & 50 & 5 \\
\hline
\end{tabular}

cretor" character and the red blood cell groups ABO. The frequency of "le le" genotype varies between different ethnic groups.

As these factors did not influence our results, the phenomenon observed cannot be accounted for by the technical or serological conditions of the study or the ethnic characteristics of the population tested. It can be related to the diabetes itself.

Schematically, the Lewis antigens, $a$ or $b$, are characterized by the presence of 1 -fucose branched in position 4 on the $\mathrm{N}$ acetyl-glucosamine of a glycoprotein, the "precursor" [12]. The presence of a Le gene is necessary for this branching: no Lewis substance is found in individuals with the le le, genotype [13]. The postulated fucosyl-transferase responsible for Lewis activity has been identified [14]. The Lewis substances are hydrosoluble and secreted in milk, saliva, plasma and other fluids such as ovarian cyst fluid. They are adsorbed from the plasma on to the red blood cells. Therefore the blood cells Lewis phenotype is dependent not only on the genotype (Le Le, Le le or le le) but possibly on genetic or environ- mental factors which may modify the expression of the gene or the adsorption of the antigens on to the red blood cells. An example of these phenotypic variations is given by the lower rate of Lewis a substance on the red blood cells of infants and pregnant women [9].

The diabetics lacking the Lewis antigens on their red blood cells are also lacking it in their saliva. All but one were concordant. Therefore their Lewis negative phenotype is unlikely to be due to a defect in the adsorption on the cells, but may be attributed to an absence of Lewis substance.

The lower frequency of Lewis antigens in the diabetic population is unlikely to reflect an environmental disturbance, otherwise some influence of the severity or the duration of the disease would have been expected. However, the results were identical in maturity and juvenile onset diabetics while the average blood sugar was higher in the latter group. They were also identical in individuals with long-standing or recent diabetes.

It seems reasonable to suppose that the observed facts are dependent on a genetic character, namely an increased frequency of the homozygous le/le genotype in the diabetic population. The increased frequency of a gene (or genes) inhibiting the expression of the Le gene is also possible. Therefore, if one accepts that the high frequency of Lewis negative phenotype observed in diabetics is genetically determined, the relative risk of developing diabetes (independent of type) for Lewis negative persons is 3.86 .

A genetic heterogeneity exists in the diabetic population. Genes located on the HLA chromosomal region appear to play a role in the susceptibility to insulin dependent diabetes [5, 6, 7]. Some ethnic groups, such as Pima Indians, are specially prone to the "maturity onset type" of diabetes [15]. At least thirty different genetic syndromes are associated with glucose intolerance either insulinopenic or not [16]. However the existence of genetic differences between diabetics does not exclude the possibility of other genetic factors contributing to the overall susceptibility to both major clinical types of diabetes. The similar frequency of the Lewis negative group 
among insulin dependent and insulin independent diabetics points to a genetic relation between these two forms of glucose intolerance. Clearly, the confirmation of these results by other laboratories would be of interest to support this conclusion.

\section{References}

1. Andersen, J., Lauritzen, E.: Blood groups and diabetes mellitus. Diabetes 9, 20-24 (1960)

2. McConnel, R. B., Pyke, D. A., Roberts, J. A. F.: Blood groups in diabetes mellitus. Br. Med. J. $1956 \mathrm{I}, 772-776$

3. Buckwalter, J. A.: Diabetes mellitus and the blood groups. Diabetes 13, 164-168 (1964)

4. Berg, K., Aarseth, S., Lundevall, J., Reinskou, T.: Blood groups and genetic serum types in diabetes mellitus. Diabetologia 3, 30-34 (1967)

5. Singal, D.P., Blajchman, M. A.: Histocompatibility (HLA) antigens, lymphocytotoxic antibodies and tissue antibodies in patients with diabetes mellitus. Diabetes 22, 429-432 (1973)

6. Cudworth, A. G., Woodrow, J. C.: Evidence for HLA linked genes in juvenile diabetes mellitus. Br. Med. J. 1975 III, 133-135

7. Nerup, J., Ortved Andersen, O., Buschard, K., Christau, B., Christy, M., Kromann, H., Platz, P., Ryder, L., Svejaard, A., Thomsen, M.: HLA-D typing in insulin dependent diabetes mellitus (Abstract). Diabetologia 13, 421 (1977)

8. Vialettes, B., Vague, Ph., Ramahandridona, G., Mercier, P.: HLA differences between insulin dependent diabetics and non diabetic low insulin responders. In: J. Dausset (Ed.): HLA and disease. INSERM Symposium June 1976, p. 147 (Abstract) Paris: INSERM Publ. 1976

9. Race, R. R., Sanger, R.: Blood groups in man, p. 659, 6th edit. Oxford: Blackwell 1975

10. Low, B.: A practical method using papain and incomplete $\mathbf{R h}$ antibodies in routine. Vox Sang. 5, 94-98 (1955)

11. Hourcadette-Goudard, J., Melis, C., Battaglini, P., Ranque, J.: Recherche systématique des anticorps chez les receveurs. In: F. Streiff (ed.): Actualités transfusionnelles, $9^{\circ}$ Cong. Nat. Transf. Sanguine June 1973, 723-731. Paris: Masson Publ 1974

12. Watkins, W. M.: Blood groups substances. Science 152, 172-181 (1966)

13. Cepellini, R.: On the genetics of secretor and Lewis characters: family study, 207-211. Proceedings of the $5^{\text {th }}$ Int. Congress of Blood Transfusion, Paris 1955

14. Grollman, E. F., Kobata, A., Ginsburg, V.: An enzymatic basis for Lewis blood types in man. Clin. Invest. 48, 1489-1494 (1969)

15. Bennett, P. H., Rushforth, N. B., Miller, M., Lecompte, P. M.: Epidemiologic studies of diabetes in the Pima Indians. Recent Prog. Horm. Res. 32, 333-376 (1976)

16. Rimoins, D. L., Neil Schimke, R.: Genetic disorders of the endocrine glands, p. 150. Saint Louis: C. V. Mosby Co. 1971

Reeived: December 2. 1977 ,

and in revised form: March 13.1977

Dr. P. Vague

Diabetes Department

University Hospital Timone

Marseille

France 